\title{
A Numerical Analysis of Single Char Particle Heated by a Laser
}

\author{
Masahiro ISHIGAKI, Mingchang $Q U^{1)}$ Masanori TOKUDA, ${ }^{1)}$ Jingzhi $\mathrm{YU}^{2)}$ and \\ Yoshiyuki KAWAZOE ${ }^{2)}$
}

Cyclotron and Radioisotope Center, Tohoku University, Aramaki-aza-aoba, Aoba-ku, Sendai, Miyagi-ken, 980-77 Japan.

1) Center for Interdisciplinary Research, Tohoku University, Katahira, Aoba-ku, Sendai, Miyagi-ken, 980-77 Japan.

2) Institute for Materials Research, Tohoku University, Katahira, Aoba-ku, Sendai, Miyagi-ken, 980-77 Japan.

(Received on December 26, 1996; accepted in final form on April 11, 1997)

\begin{abstract}
An unsteady state boundary layer model was developed in order to analyse the combustion of single char particles in radiation fields. The model is based on the following assumptions, a spherical char particle with small diameter is combusted at atmospheric pressure, the temperature difference between the surface and the inside of the particle is negligible, particle diameter shrinks due to the reaction on the char surface, the surrounding gas is stagnant, but Stefan flow is taken into consideration and bulk gas flow is neglected. The model predicts the particle temperature increase and the distributions of gas temperature and gas components in the boundary layer. The computed distribution of gas component proves clearly that the reaction rate is mainly controlled by oxygen diffusion in the boundary layer except during the initial heating and reaction. Using the simulation model, the effects of particle size, oxygen content in bulk gas and input laser power is discussed. The results predict that smaller particles heat up faster in initial heating and higher laser input has the same effect. Further, it is shown that a higher oxygen content raises the sustained combustion temperature and shortens the combustion period.
\end{abstract}

KEY WORDS: char; laser; combustion; simulation model.

\section{Introduction}

Pulverized coal combustion comprises two overlapping processes namely the decomposition and combustion of volatile matter, and the combustion of char. Though these two processes affect each other, they need to be investigated separately for analysing the reaction in combustion processes and for developing combustion technology of pulverized coal. Zhang et al. ${ }^{1)}$ proposed ignition mechanisms where the precedence of ignition between heterogeneous reaction on particle surface and homogeneous reaction in gas phase depends on the volatile matter content. In practical combustion processes, according to Lassat de Pressigny et al., ${ }^{2)}$ char combustion begins after exhaustion of volatile matter and maintains for much longer duration in blast furnace coal injection processes. Thus, in the context of effective combustion, it is clear that char particle combustion is the most important process.

We have already developed a new device for rapid heating using $\mathrm{CO}_{2}$ laser in order to examine coal combustion without any influence of volatile combustion. The temperature increase of coal particles has been examined. ${ }^{3)}$ In this work, a new simulation model is developed based on the experiments to describe the char combustion process and the effects of several operational parameters by referring to the experimental results of coal combustion.

Although the mathematical combustion model of single carbon particles has been studied since 1920's, little is known about the unsteady state of the process. In recent years, there has been a renewal of interest in the unsteady state combustion model with a boundary layer which can be described in terms of the distribution change of gas contents, gas temperature and particle temperature.

The first model ${ }^{4-6)}$ is based on an energy balance on the particle surface and considers the combustion as time proceeds. By the simple models, the analytical solutions for particle temperature are given as a function of time. But the models do not consider the distribution of gas temperature and composition around a particle. Both the heterogeneous reaction on particle surface and the homogeneous reaction in gas phase surrounding a particle were coupled for analysis of the combustion in steady state or quasi-steady state ${ }^{7-11)}$ with boundary layers. In order to simplify the analysis of surrounding gas phase, a single film model and a double film were proposed for small particles and large particles, respectively.

In the rate control process in combustion, generally diffusion of gas is dominant at higher temperatures and chemical reaction is dominant at lower temperatures. ${ }^{12)}$ In the complicated combustion phenomena which occur when pulverized coal and char are blown into a high temperature radiation field, the particle size, its physical properties, the gas temperature and gas composition all change with time. Steady state models or quasi-steady state models are useless for analysing the rate control process.

Recently an unsteady state combustion model has been 
developed by Ösüm et al. ${ }^{13)}$ In this model, the surrounding gas space is divided into small control volumes. Mass transfer, heat transfer and chemical reactions are balanced over small time periods. The solutions are obtained by numerical analysis. Although the analysis requires long time even by high speed computers, it is very important to understand the functions of gas composition and temperature distribution in detail. The model is based on experimental results of pulverized coal combustion in an entrained flow reactor by Waters et al. ${ }^{14)}$ and proved that the effect of the $\mathrm{CO}$ combustion to $\mathrm{CO}_{2}$ in gas phase on particle temperature should not be ignored. Using a similar method, Yamamoto et al. ${ }^{15}$ ) analysed $\mathrm{N}_{2} \mathrm{O}$ synthesis and its decomposition during single coal particle combustion.

In results computed from the unsteady state models, some oxygen remains unreacted near the particle surface. This contradicts experimental results which show that the combustion is diffusion controlled at high temperature. ${ }^{16)}$ Unsteady state model must be refined further and evaluated against the results from experiments using controlled combustion technique and measurement systems.

More recently, laser heating techniques are employed to investigate the combustion process. ${ }^{17-19)}$ Using this technique, a substantial amount of understanding on the complicated phenomena of coal combustion has been achieved. In this work, an unsteady state boundary layer simulation model of a single char particle heated by $\mathrm{CO}_{2}$ laser is developed and the effect of particle size, radiation intensity and oxygen content of surrounding gas is discussed.

\section{Mathematical Model}

\subsection{Outline of the Model}

The model is illustrated in Fig. 1. A single char particle is heated externally by a laser beam. Three chemical reactions in Table $\mathbf{1}$ are considered in this model. Char is exhausted by the heterogeneous reactions shown in (1) and (2) on the particle surface. The homogeneous reaction shown in (3) produces $\mathrm{CO}_{2}$ in the gas phase of the boundary layer.

The symbols $\beta_{i}, M_{i}, V_{j}$ in Eq. (3), introduced to match the dimensions with those of (1) and (2), are explained in the nomenclature.

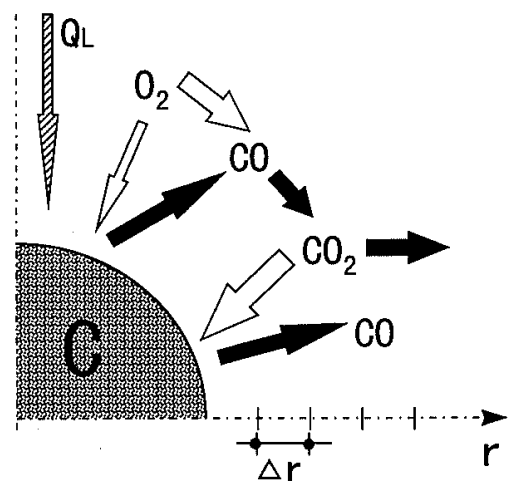

Fig. 1. Schematic representation of single particle combustion model.
Table 1. Chemical reactions and their kinetic data.

\begin{tabular}{|c|c|}
\hline Reaction & Kinetic data $(\mathrm{kg} / \mathrm{s})$ \\
\hline $2 \mathrm{C}+\mathrm{O}_{2}=2 \mathrm{CO}$ & $\begin{aligned} R_{1}= & 87100 \exp \left(-17976 / T_{\mathrm{p}}\right) P_{\mathrm{O}_{2}} S \\
& T_{\mathrm{p}} \leqq 1650 \mathrm{~K}^{20)} \\
R_{1}= & \left(3.85 \times 10^{-3} T_{\mathrm{p}}-4.9\right) P_{\mathrm{O}_{2}} S \\
& T_{\mathrm{p}}>1650 \mathrm{~K}\end{aligned}$ \\
\hline $\begin{array}{l}\mathrm{C}+\mathrm{CO}_{2}=2 \mathrm{CO} \\
2 \mathrm{CO}+\mathrm{O}_{2}=2 \mathrm{CO}\end{array}$ & $\begin{array}{l}R_{2}=6 \times 10^{11} T_{\mathrm{p}}^{-1} \exp \left(-29794 / T_{\mathrm{p}}\right) P_{\mathrm{CO}_{2}} S^{7)} \ldots(2) \\
R_{3 i}=8.3 \times 10^{9} \exp \left(-1303 / T_{\mathrm{g}}\right) C_{\mathrm{O}_{2}} C_{\mathrm{Co}_{i}} \beta_{i} M_{i} V_{j}^{21)}\end{array}$ \\
\hline
\end{tabular}

The model assumes; (1) spherical single particles, (2) temperature difference between the surface and the inside of particle is negligible as the sample's diameter is small, (3) solid carbon reacts only on the surface, the particle shrinks uniformly, and an reacted shell of ash is leftover, (4) atmospheric pressure, (5) Stefan flow occurs in a stagnant gas mixture of nitrogen and oxygen.

\subsection{Equations in the Model}

Under the assumptions, equation of state (4), continuity equation (5), mass and energy conservation for solid particle ((6) and (7)), mass and energy conservation in a gas phase $((8)$ and (9)) are given in control volume $j$. These equation can be solved simultaneously by numerical computation.

$$
\begin{array}{r}
\rho_{\mathrm{g}}=\frac{P \bar{M}}{R T_{\mathrm{g}}} \ldots \cdots \\
\frac{\partial \rho_{\mathrm{g}}}{\partial t}+\frac{1}{r^{2}} \frac{\partial}{\partial r}\left(r^{2} \varphi\right)=0 \\
-\frac{d\left(\rho_{\mathrm{p}} V_{\mathrm{p}}\right)}{d t}=R_{1}+R_{2}
\end{array}
$$

$$
\frac{d}{d t}\left(\rho_{\mathrm{p}} V_{\mathrm{p}} C p_{\mathrm{p}} T_{\mathrm{p}}\right)=\frac{1}{4} \alpha Q_{\mathrm{L}} S-Q_{\mathrm{N}}-Q_{\mathrm{rs}}+\xi\left(Q_{1}+Q_{2}\right) \ldots
$$

$\frac{\partial}{\partial t}\left(\rho_{\mathrm{g}} Y_{i}\right)+\frac{1}{r^{2}} \frac{\partial}{\partial r}\left(r^{2} \varphi Y_{i}\right)=\frac{1}{r^{2}} \frac{\partial}{\partial r}\left(r^{2} D_{i} \rho_{\mathrm{g}} \frac{\partial Y_{i}}{\partial r}\right)+R_{3 i}$

$$
\begin{array}{r}
\frac{\partial}{\partial t}\left(\rho_{\mathrm{g}} C p_{\mathrm{g}} T_{\mathrm{g}}\right)+\frac{1}{r^{2}} \frac{\partial}{\partial r}\left(r^{2} \varphi C p_{\mathrm{g}} T_{\mathrm{g}}\right)=\frac{1}{r^{2}} \frac{\partial}{\partial r}\left(r^{2} \lambda \frac{\partial T_{\mathrm{g}}}{\partial r}\right) \\
+Q_{3}+Q_{d}+Q_{\mathrm{rg}}+(1-\xi)\left(Q_{1}+Q_{2}\right) \ldots \ldots \ldots \ldots \ldots . . . .(9)
\end{array}
$$

where $Q_{\mathrm{L}}$ is input laser energy, $Q_{1}, Q_{2}$ and $Q_{3}$ are the heats of Reactions (1), (2) and (3), respectively. The proposed distribution laws of the surface reaction heat depend on the quoted reactor models; the heat is given only to the particle ${ }^{22)}$ or divided between particle and gas phase according to some distribution law. ${ }^{23-25)}$ The heat is defined here to be apportioned equally between the particle and the gas phase as in Luo et al. ${ }^{25)} Q_{N}$ is the heat conductivity given in Eq. (11). $Q_{\mathrm{rs}}$ is the total radiation energy on the particle surface calculated by Eq. (12) where input radiation from $\mathrm{CO}_{2}$ gas is taken into account. $Q_{\mathrm{d}}$ is the heat resulting from molecular diffusion of each gas components and is given by Eq. (13). $Q_{\mathrm{rg}}$ is the change of radiation energy in a control volume $j$ given by Eq. (14). 


$$
\begin{aligned}
& \varphi=\rho_{\mathrm{g}} v \\
& Q_{N}=h\left(T_{\mathrm{p}}-T_{\mathrm{g}}\right) S \\
& Q_{\mathrm{rs}}=\varepsilon_{\mathrm{p}} \sigma\left(T_{\mathrm{p}}^{4}-T_{0}^{4}\right) S-\sum_{j}\left[\varepsilon_{\mathrm{p}} \varepsilon_{\mathrm{g} j} \sigma T_{\mathrm{g} j}^{4} S \prod_{\delta}\left(1-\varepsilon_{\delta}\right)\right] \ldots \\
& Q_{\mathrm{d}}=\sum_{i}\left\{\left[S_{\mathrm{v}} \rho_{\mathrm{g}} D_{i} \frac{\partial Y_{i}}{\partial r} \int_{T_{\mathrm{o}}}^{T} C p_{\mathrm{g} i} d T\right]_{j+\Delta r / 2}\right. \\
& \left.-\left[S_{\mathrm{v}} \rho_{\mathrm{g}} D_{i} \frac{\partial Y_{\mathrm{i}}}{\partial r} \int_{T_{\mathrm{o}}}^{T} C p_{\mathrm{g} i} d T\right]_{j-\Delta r / 2}\right\} \\
& Q_{\mathrm{rg}}=\frac{\sigma}{V_{j}}\left\{\varepsilon_{\mathrm{g}} \varepsilon_{\mathrm{p}} S\left(T_{\mathrm{p}}^{4}-T_{0}^{4}\right) \prod_{\delta}\left(1-\varepsilon_{\delta}\right)-2 \varepsilon_{\mathrm{g}} S_{\mathrm{v}} T_{\mathrm{g}}^{4}\right. \\
& \left.+\sum_{k}\left[\varepsilon_{\mathrm{g}} \varepsilon_{\mathrm{g} k} S_{\mathrm{v} k} T_{\mathrm{g} k}^{4} \prod_{\delta}\left(1-\varepsilon_{\delta}\right)\right]\right\}
\end{aligned}
$$

where $\varepsilon_{\mathrm{g}}$ is emissivity of $\mathrm{CO}_{2}$ gas derived from Hottel's chart. ${ }^{24)}$ Other symbols are listed in the nomenclature.

Boundary conditions are derived from the assumption that the composition and temperature of gas is uniform outside the $N$ control volumes. $N$ indicates the boundary layer thickness and the thickness depends on the gas velocity around the particle. In order to examine impact of the thickness, simulation was carried out for different boundary layer thicknesses. The results show the nature of the curves of gas temperature and gas components do not change significantly, but for minor changes in the gradient. In this simulation, we resulted the thickness of $1.4 \mathrm{~mm}$ as the most appropriate from the experimental system. ${ }^{3)}$

The boundary conditions are follows;

$$
\begin{aligned}
& T_{\mathrm{g}}=T_{0}=\text { const. } \quad \text { in } \quad j>N \\
& \frac{\partial Y_{i}}{\partial r}=0 \quad \text { in } \quad j>N
\end{aligned}
$$

The initial conditions are follows;

$$
\begin{gathered}
T_{\mathrm{p}}=T_{\mathrm{g}}=T_{0} \quad \text { at } \quad t=0 \\
Y_{i j}=Y_{i 0} \quad \text { at } \quad t=0 .
\end{gathered}
$$

The equations were solved numerically by Thomas's exponential method after making differential equations by implicit method. A super computer (HITAC S$3800 / 380$ ) was used for the highly non-linear problem to get numerical solutions. The significant parameters used in the calculation are shown in Table 2.

\section{Results and Discussion}

\subsection{Combustion Process and Simulation Model Predic- tions}

Figure 2 shows the simulated profiles of the temperatures and gas components in the control volume adjacent to the particle surface, namely, at the distance of $0.05 \mathrm{~mm}$ from the surface. In this computation, we have used $1.85 \mathrm{~W} / \mathrm{mm}^{2}$ laser input, $21 \%$ oxygen content of initial surrounding and bulk gas, and $0.2 \mathrm{~mm}$ particle diameter.

In Fig. 2 particle temperature $T_{\mathrm{p}}$ increases with laser heating at first and gas temperature $T_{\mathrm{g}}$ follows up gradually due to radiation from the particle surface.
Table 2. Physical data used in the calculations.

\begin{tabular}{ll}
$T_{\mathrm{p}(t=0)}=298(\mathrm{~K})$ & $T_{\mathrm{g} i t(t=0)}=298(\mathrm{~K})$ \\
$\alpha=0.95$ & $\varepsilon_{\mathrm{p}}=0.95$ \\
$\rho_{\mathrm{p}}=1060\left(\mathrm{~kg} / \mathrm{m}^{3}\right)$ & $\xi=0.5$ \\
$\sigma=5.669 \times 10^{-8}\left(\mathrm{~W} / \mathrm{m}^{2} \cdot \mathrm{K}^{4}\right)$ & \\
$C p_{\mathrm{p}}=837+1.482(T-273)-4.4 \times 10^{-4}(T-273)^{2}(\mathrm{~J} / \mathrm{kg} \cdot \mathrm{K})$ \\
$C p_{\mathrm{CO}_{2}}=44.14+9.04 \times 10^{-3} T-8.54 \times 10^{5} T^{-2}(\mathrm{~J} / \mathrm{mol} \cdot \mathrm{K})$ \\
$C p_{\mathrm{O}_{2}}=30+4.2 \times 10^{-3} T-1.7 \times 10^{5} T^{-2}(\mathrm{~J} / \mathrm{mol} \cdot \mathrm{K})$ \\
$C p_{\mathrm{CO}}=28.4+4.1 \times 10^{-3} \mathrm{~T}-0.46 \times 10^{5} T^{-2}(\mathrm{~J} / \mathrm{mol} \cdot \mathrm{K})$ \\
\hline
\end{tabular}

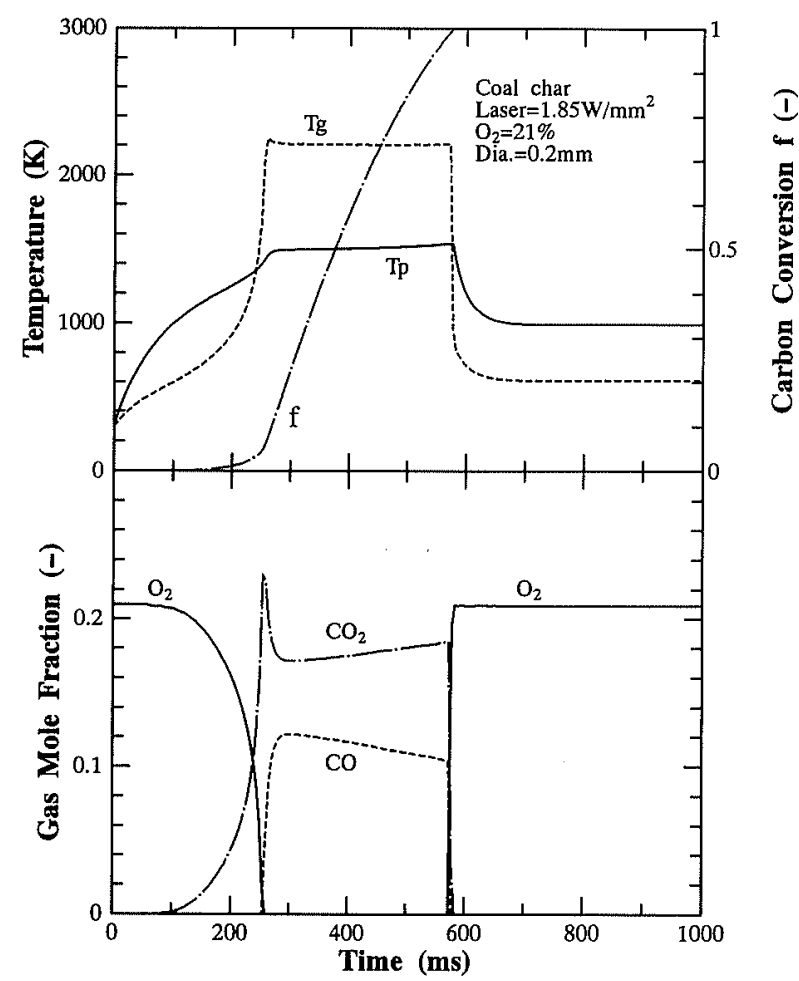

Fig. 2. Simulation results on the change of temperature and gas contents. $T_{\mathrm{g}}$ and gas contents are at $0.05 \mathrm{~mm}$ from the particle surface.

Approximately $200 \mathrm{~ms}$ later, the temperature increases rapidly due to the acceleration of chemical reactions and an inflection is observed on the temperature curve. The particle burnt out after a stable state from 260 to $560 \mathrm{~ms}$ and the temperature reduced to that of the resultant ash.

The configuration of char particle temperature curve in Fig. 2 is similar to that of experimental temperature curve in Fig. 3, however the experiment was performed with several carbon particles. ${ }^{3)}$ In our previous work, we reported that it is more convenient to analyse the carbon particle combustion by dividing the process into three stages along the heating curves as shown in Fig. 3 . The simulated particle temperature curve reinforces that observation. The part before the point of inflection is the 'initial heating stage', the stable temperature part is the 'sustained combustion stage' and the intermediate portion containing the ignition point is the 'ignition stage'. Henceforth, we will refer to these three parts in Fig. 3 to explain combustion process.

In the gas phase, the gas temperature $T_{\mathrm{g}}$ at $0.05 \mathrm{~mm}$ from the surface is lower than the particle temperature $T_{\mathrm{p}}$ at the beginning. $T_{\mathrm{g}}$ goes up rapidly with increasing $T_{\mathrm{p}}$ and rises higher than $T_{\mathrm{p}}$ in the sustained combustion 


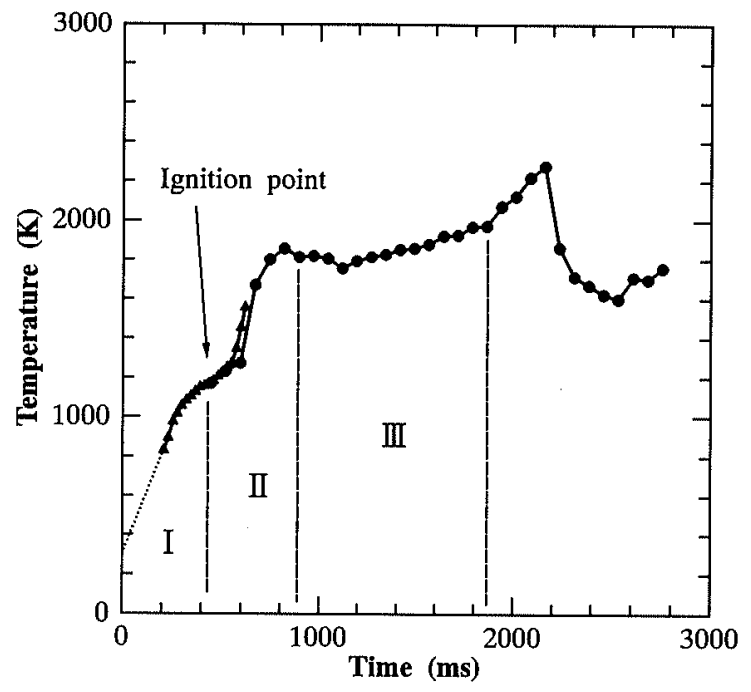

Fig. 3. Typical experimental temperature curves of carbon particles and separated combustion stages. I is initial heating stage, II is ignition stage and III is sustained combustion stage. (Laser input $=2.59 \mathrm{~W} / \mathrm{mm}^{2}, D_{\mathrm{p}}=$ $0.2 \mathrm{~mm}, 20$ particles, $\mathrm{O}_{2}=50 \%$ )

stage. Accumulated oxygen content decreases with increase of particle temperature. It is obvious that the oxygen diffusion from bulk gas is slower than the oxygen consumption on the surface shown in Eq. (1). In the sustained combustion stage, the oxygen content falls to $10^{-4}$. To the best of our knowledge, to date, this result has not been obtained. On the other hand $\mathrm{CO}$ content rises as oxygen content falls. At the same time, $\mathrm{CO}_{2}$ increases drastically and then takes a small dip because of insufficient oxygen supply. It is clear that surrounding oxygen is consumed rapidly at the beginning by Eq. (1) and diffused oxygen from bulk gas reacts with $\mathrm{CO}$ in the gas phase. In this simulation, at around $260 \mathrm{~ms}$ i.e. after consumption of the initial oxygen, the reaction rate is controlled by oxygen diffusion.

Because oxygen supply from bulk gas is insufficient, the endothermic reaction of Eq. (2) dominates on the surface rather than the exothermic reaction of Eq. (1). Reaction (2) suppresses the surface temperature of the particle. In the gas phase, exothermic reaction of Eq. (3) occurs this results in gas heating faster than the particle. Comparison of specific heat $C p$, char (1.65) and gas (1.2) at around $1000 \mathrm{~K}$, would be insignificant to explain the large gradient in temperature between the gas and the particle.

The particle temperature curve is similar to the predictions by Ösüm et al ${ }^{13)}$ and Yamamoto et al. ${ }^{15)}$ The appearance of the point of inflection caused by acceleration of reaction and the combustion temperature range approximately $1500 \mathrm{~K}$, tallies nicely. However the radiation conditions are assumed to be that of an entrained flow reactor in Ref. 13) and a swirling flow turbulent coal combustor in Ref. 15). Sustained combustion is also observed in their works, though there is a slight and gradual temperature decrease. But their results predicted an accumulation of oxygen up to 2-4\% in the gas phase at maximum temperature. It can be explained that because the reaction shown in (3) is not as fast compared to gas diffusion, oxygen accumulates

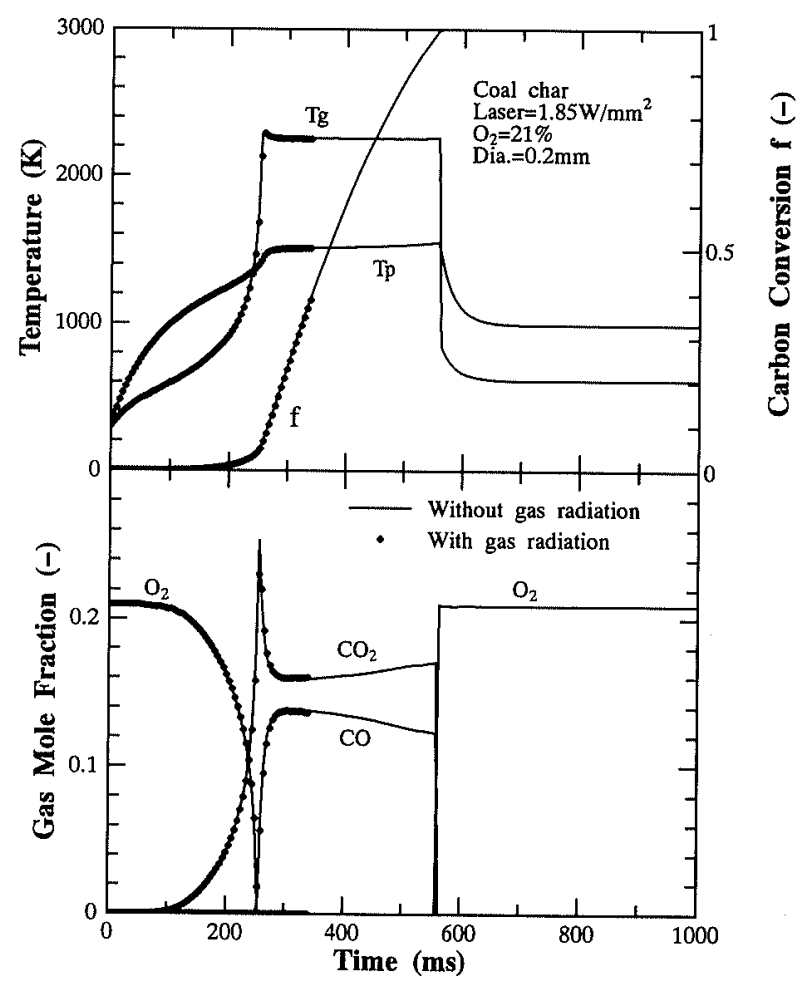

Fig. 4. Effects of gas radiation: change of temperature gas component. $T_{\mathrm{g}}$ and gas contents are at $0.05 \mathrm{~mm}$ from the particle surface.

and the heat by reaction shown in (3) cannot sustain the temperature. Ösüm et al. ${ }^{13)}$ carried out simulations for a gas composition which contained $\mathrm{H}_{2} \mathrm{O}$. Because the chemical reaction rate constant for a composition containing $\mathrm{H}_{2} \mathrm{O}$ is smaller than that of a heterogeneous Reaction (3) which does not contain $\mathrm{H}_{2} \mathrm{O}$, accumulated oxygen was higher than our results. Kanury's description that oxygen diffusion is the key to rate control in combustion at high temperatures supports our results. ${ }^{12)}$ But the estimation of the rate of the reaction shown in (3) is an open problem. It needs to be done by comparing accurate experiments with precise models.

\subsection{Radiant Heat from $\mathrm{CO}_{2}$ Gas}

For computational purpose, simplification of the simulation model is required. To ensure that the calculated results are not affected by the simplification, we estimated the impact of two aspects of this simulation model.

The previous works ${ }^{13,15)}$ on unsteady state model ignore the heat transfer by radiation from gas. And Yamamoto et al. ${ }^{15)}$ did not consider the heat transfer by molecular diffusion. But, it will be useful to estimate the effect of the heat transfer by molecular diffusion on the simulation model.

Figure 4 shows the effect of radiant heat from $\mathrm{CO}_{2}$ gas on the temperatures and the gas composition adjacent to the particle surface. In the case with $21 \%$ oxygen as shown in Fig. 4, it is clear that the effect of radiant heat from $\mathrm{CO}_{2}$ gas on the temperatures and gas composition is negligibly small. Furthermore, same result is given in the case with pure oxygen. Thus we drop the radiant from the gas phase in our simulation model. 


\subsection{Heat Transfer by Molecular Gas Diffusion}

Let us now attempt to estimate the impact of heat transfer by molecular gas diffusion. Figure 5 gives us the predicted curves of temperature changes and gas composition changes with and without the heat transfer. In the case with the heat transfer, the sustained combustion temperature shifts slightly lower and combustion period extends $4 \%$. The reason for this is not difficult to ex-

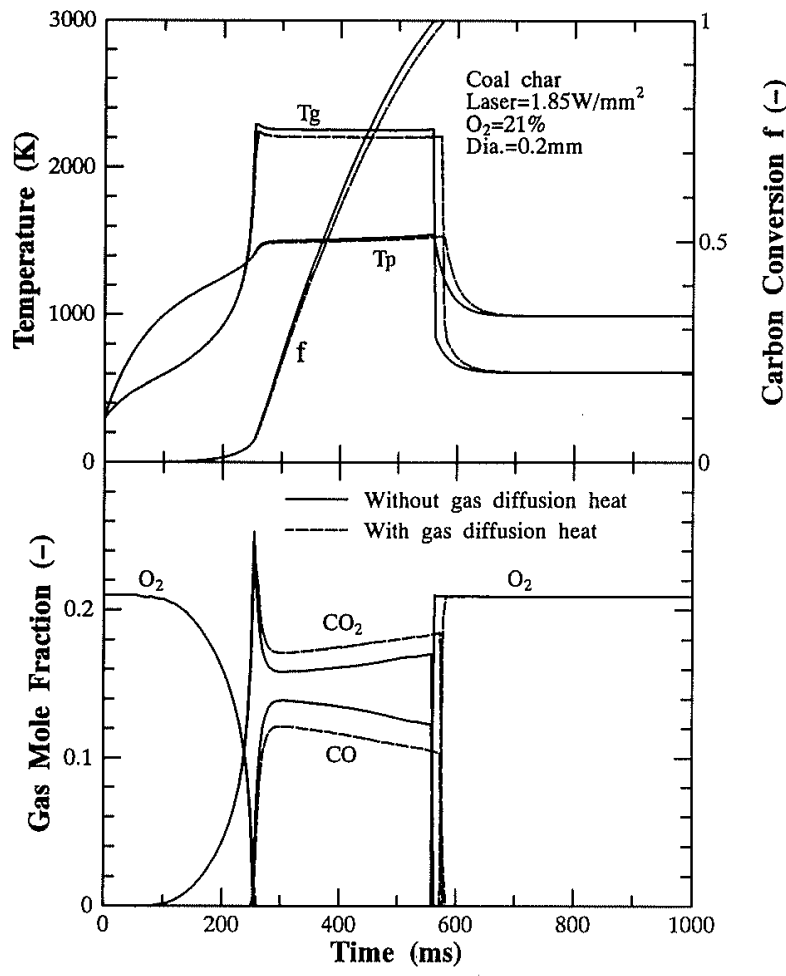

Fig. 5. Effect of heat transfer by molecular gas diffusion: change of the temperature and gas component change. $T_{\mathrm{g}}$ and gas contents are at $0.05 \mathrm{~mm}$ from the particle surface. plain: since the heat generated by Reaction (1) diffuses accompanied by molecular diffusion, the temperature in the gas phase and that on the particle surface goes down slightly and Reaction (1) is suppressed. Thus, if a model does not include the heat transfer by molecular diffusion, the predicted temperatures of particle and gas phase are likely to be a little higher than the true temperatures. And also $\mathrm{CO}$ and $\mathrm{CO}_{2}$ content can be obtained higher and lower respectively in sustained combustion stage. The results also show a difference of $1.5 \%$ in particle temperature, $3 \%$ in gas temperature, $12 \%$ in $\mathrm{CO}$ concentration and $10 \%$ in $\mathrm{CO}_{2}$ concentration (Fig. 5). The nature of the curve is not significantly affected.

\subsection{Distribution of Gas Temperature}

Figures 6(a)-6(d) show the distribution change of gas temperature and gas composition during heating. The gas temperature decreases monotonically with increasing distance from the particle at the beginning of the combustion and the distribution shifts upward with time. A temperature peak appears at a short distance from the surface after $260 \mathrm{~ms}$ when sustained combustion begins (Fig. 2). At the same time, oxygen content reduced to near zero at the surface. CO content shift upward in contrary synchronizing with oxygen. The distribution of $\mathrm{CO}_{2}$ is lifted in a manner similar to the gas temperature and a peak corresponding to the gas temperature appears.

Figure 7 shows a typical distribution of gas temperature at $300 \mathrm{~ms}$ in sustained combustion stage. Concentration of accumulated oxygen falls to near zero at $0.05 \mathrm{~mm}$ from the surface and rises gradually up to bulk concentration as distance increases. It can be assumed that the diffusing oxygen from bulk gas to the surface has reacted rapidly with $\mathrm{CO}$ by (3) as far as $0.05 \mathrm{~mm}$ and, oxygen and $\mathrm{CO}$ do not accumulate near the particle surface. Owing to the insufficiency of oxygen after the initial oxygen consumption, $\mathrm{CO}_{2}$ is consumed by the

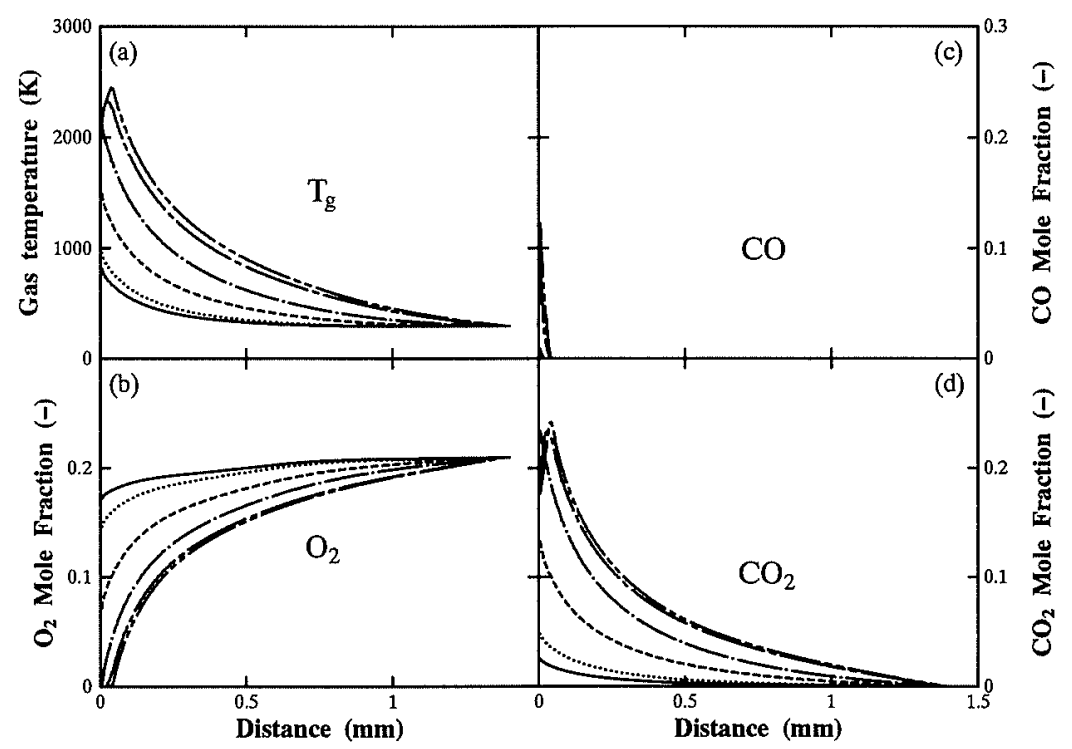

Fig. 6. Simulation results on the distribution changes of gas temperature and contents. ( Laser input $=1.85 \mathrm{~W} / \mathrm{mm}^{2}$, particle diameter $=0.2 \mathrm{~mm}, \mathrm{O}_{2}=21 \%$ )

(a) Gas temperature, (b) $\mathrm{O}_{2}$ mole fraction, (c) $\mathrm{CO}$ mole fraction, (d) $\mathrm{CO}_{2}$ mole fraction.

- at $170 \mathrm{~ms}, T_{\mathrm{p}}=1191 \mathrm{~K}, D_{\mathrm{p}}=0.1997 \mathrm{~mm}, \cdots$ at $200 \mathrm{~ms}, T_{\mathrm{p}}=1259 \mathrm{~K}, D_{\mathrm{p}}=0.1990 \mathrm{~mm},-\cdots--$ at $240 \mathrm{~ms}$,

$T_{\mathrm{p}}=1369 \mathrm{~K}, D_{\mathrm{p}}=0.1980 \mathrm{~mm},-$ - - at $250 \mathrm{~ms}, T_{\mathrm{p}}=1420 \mathrm{~K}, D_{\mathrm{p}}=0.1970 \mathrm{~mm},--$ at $260 \mathrm{~ms}, T_{\mathrm{p}}=1463 \mathrm{~K}$,

$D_{\mathrm{p}}=0.1950 \mathrm{~mm},---$ at $300 \mathrm{~ms}, T_{\mathrm{p}}=1491 \mathrm{~K}, D_{\mathrm{p}}=0.1860 \mathrm{~mm}$ 
endothermic Reaction (2). Thus CO content increases by Reaction (2) and $\mathrm{CO}_{2}$ content decreases near the surface.

\subsection{Oxygen Concentration}

The simulated result with different oxygen concentration of bulk gas are shown in Figs. 8(a)-8(f). In Fig. $8(a)$, the same observation applies to the form of the curves, i.e. ignition point and sustained combustion appear except in the case of pure nitrogen. But the oxygen increase has some significant impacts. Viz an earlier appearance of ignition, an acceleration of particle temperature increase after ignition, higher gas and par-

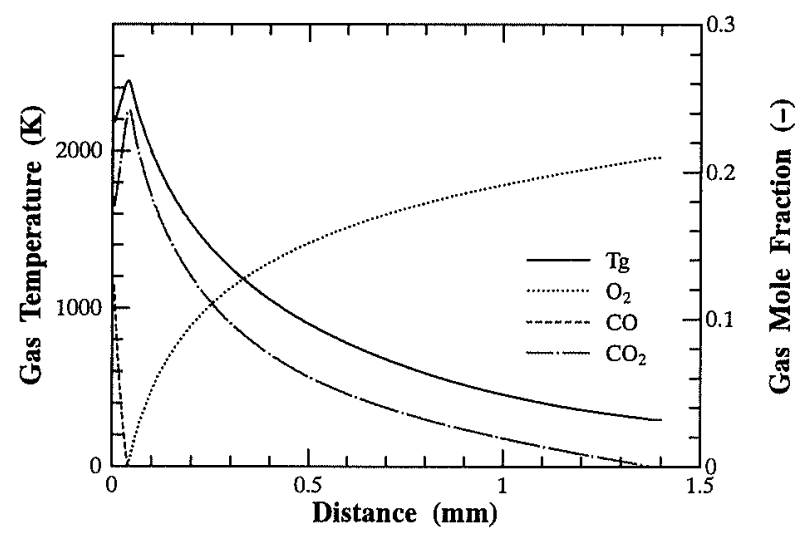

Fig. 7. Distribution of surrounding gas contents and temperature at $300 \mathrm{~ms}$. (Laser input $=1.85 \mathrm{~W} / \mathrm{mm}^{2}, D_{\mathrm{p}}=$ $0.2 \mathrm{~mm}, \mathrm{O}_{2}=21 \%$ ) ticle temperature level during sustained combustion. The effects of oxygen concentration as predicted by the model tally well with the experimental results, ${ }^{3)}$ however the experimental results were obtained with the several coals.

The near zero accumulation of oxygen at the surface, even in $100 \%$ oxygen, implies that a higher oxygen flux is accompanied by a faster rate of Reaction (1). Thus total combustion period reduces with increased oxygen content.

\subsection{Input Radiation Energy}

Figures 9(a)-9(f) show the change of the temperatures and gas contents with different input laser power. In this figure, it is observed that the higher laser input results in a higher heating rate during the initial heating stage and raises the sustained combustion temperature level slightly. Higher input laser energy will have little effect on the gas temperature and the time period of sustained combustion. The experimental results showing that laser input affects the heating rate only in initial stage is also predicted in this model.

\subsection{Particle Size}

Substituted char particle diameter was also changed in the simulation. To avoid the temperature difference between the surface and the inside of a particle, the simulation was carried out for diameters up to $0.3 \mathrm{~mm}$. Figures 10(a)-10(f) show the predicted results. Smaller particle size increases the temperature more rapidly dur-

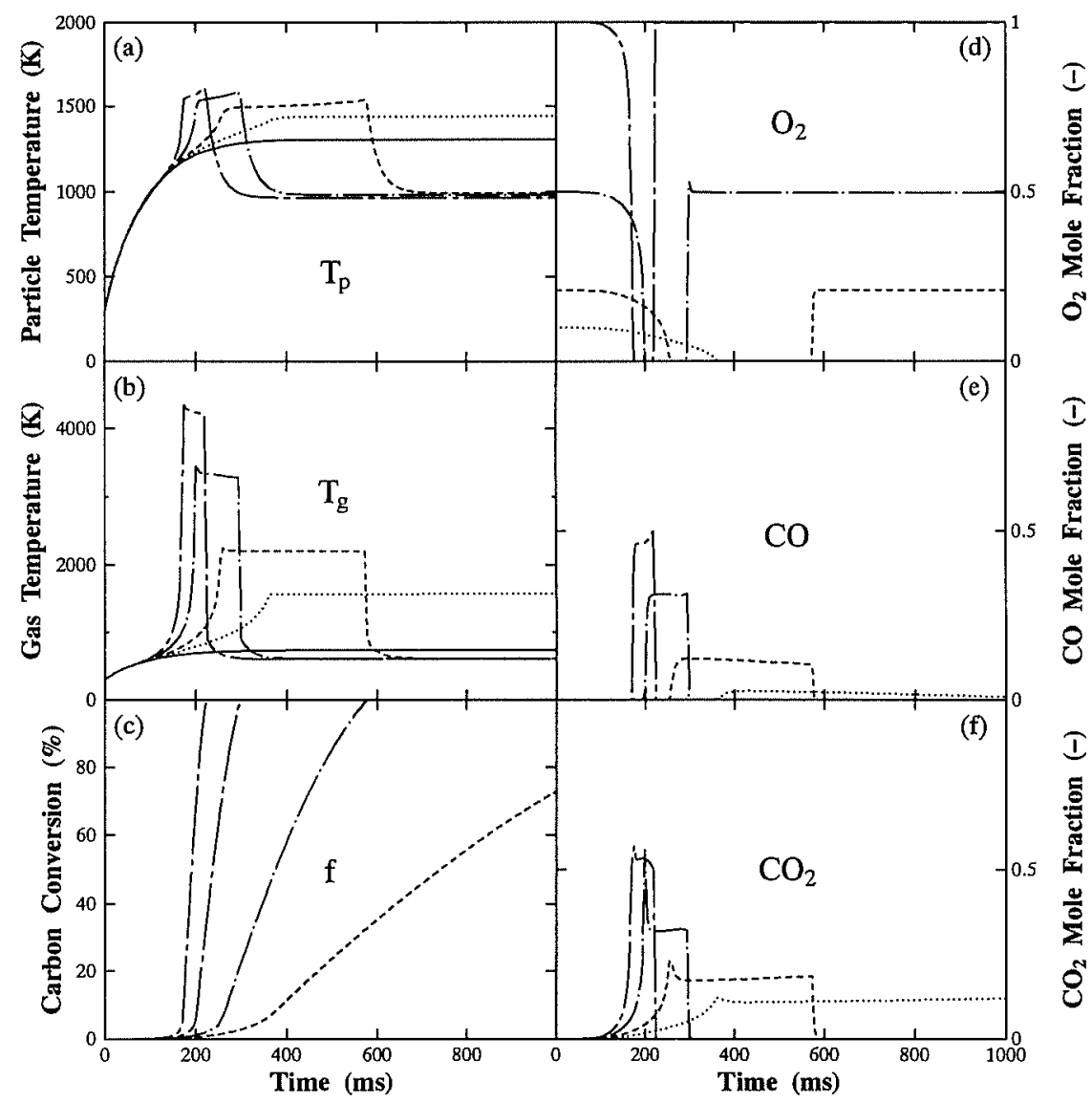

Fig. 8. Effects of oxygen concentration on coal char combustion. (Laser input $=1.85 \mathrm{~W} / \mathrm{mm}^{2}, D_{\mathrm{p}}=0.2 \mathrm{~mm}$ ) (a) Particle temperature, (b) gas temperature, (c) carbon conversion, (d) $\mathrm{O}_{2}$ mole fraction, (e) $\mathrm{CO}$ mole fraction, (f) $\mathrm{CO}_{2}$ mole fraction

Gas temperature and contents are at $0.05 \mathrm{~mm}$ from the particle surface. - pure $\mathrm{N}_{2}, \cdots 10 \% \mathrm{O}_{2}, \ldots 21 \% \mathrm{O}_{2}, \ldots-\ldots 0 \mathrm{O}_{2}, \ldots$ pure $\mathrm{O}_{2}$ 


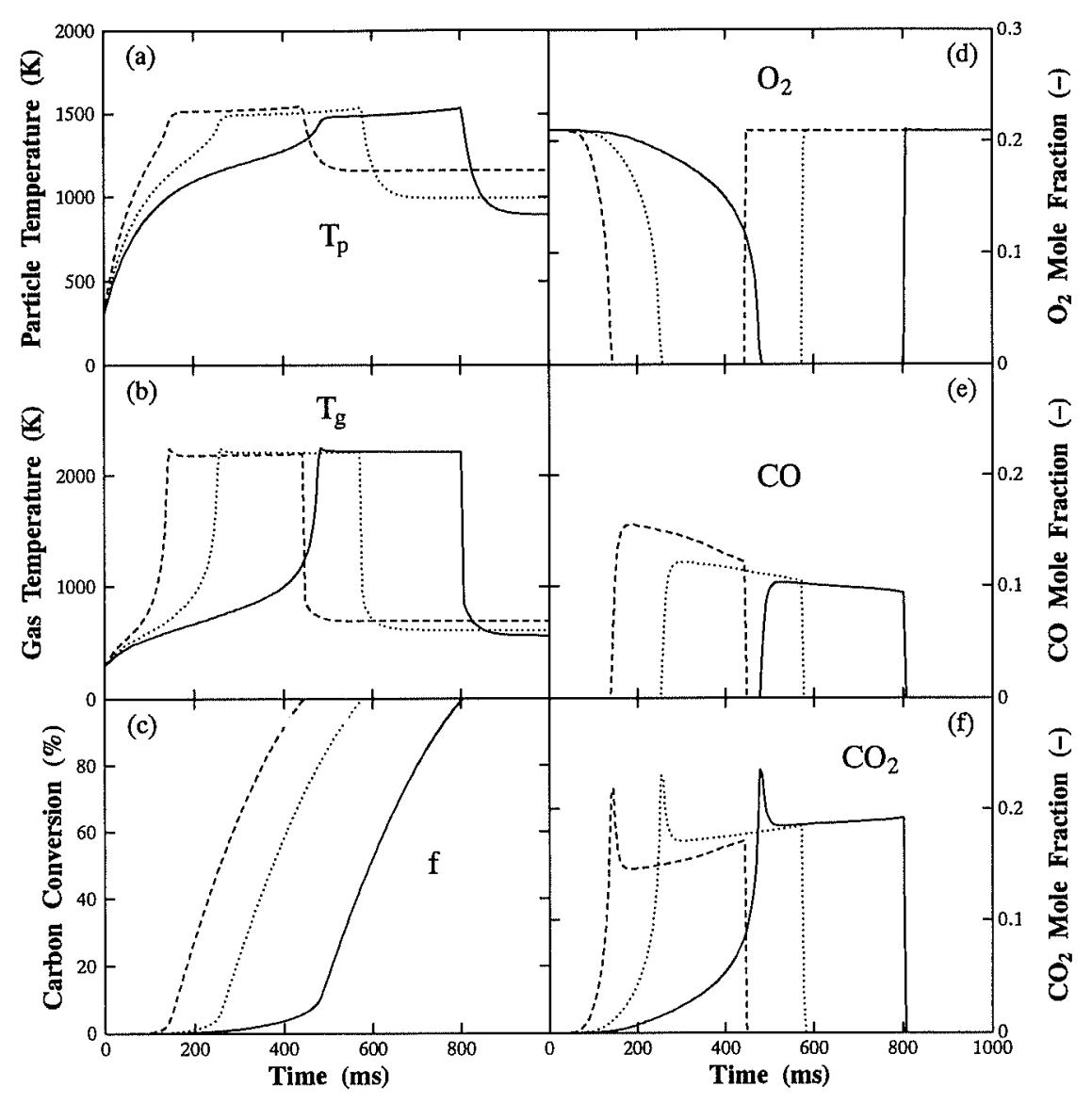

Fig. 9. Effects of laser input on coal char combustion. ( $D_{\mathrm{p}}=0.2 \mathrm{~mm}, \mathrm{O}_{2}=21 \%$ )

(a) Particle temperature, (b) gas temperature, (c) carbon conversion, (d) $\mathrm{O}_{2}$ mole fraction, (e) CO mole fraction, (f) $\mathrm{CO}_{2}$ mole fraction

Gas temperature and contents are at $0.05 \mathrm{~mm}$ from the particle surface.

$-1.48 \mathrm{~W} / \mathrm{mm}^{2}, \cdots 1.85 \mathrm{~W} / \mathrm{mm}^{2}, \cdots 2.59 \mathrm{~W} / \mathrm{mm}^{2}$

ing the initial heating stage and raises the temperature level slightly in sustained combustion. Compared to larger particles, smaller particles receive more energy per unit mass and offer a larger reaction area per unit mass. Thus small particles heat up more rapidly. Of course larger particles take longer to burn out.

It is predicted that particle size gives no significant effect on gas temperature (Fig. 10(b)), larger particles raise the $\mathrm{CO}$ content little higher (Fig.10(e)) and reduce the $\mathrm{CO}_{2}$ content in sustained combustion (Fig. 10(f)). The effects are explained not from equilibrium of gas contents, but from the larger volume of reacting mass on the particle surface owing to the larger reacting area.

We have concluded experimentally with coal that the particle diameter has not significant effect on sustained temperature. It is confirmed by the simulated results in Fig. 10(a).

\section{Conclusion}

An unsteady state combustion model, which takes into account the homogeneous reaction of surrounding gas, was developed to understand the small char particle combustion in laser radiation. The heat radiation of $\mathrm{CO}_{2}$ gas is negligibly small in the model. The heat transfer by gas molecular diffusion was found significant and has been retained in the simulation.
The simulation results predict the following;

The gas temperature is predicted to be higher than particle temperature. In the sustained combustion stage, surface reaction rate is controlled by Reaction (2). Because $\mathrm{CO}$ reacts rapidly with diffused oxygen, the accumulated concentration of $\mathrm{CO}$ and oxygen falls to nearly zero at close to the particle surface. $\mathrm{CO}_{2}$ content has a peak near the particle surface.

In addition, the effects of particle size, laser input energy and oxygen contents on the combustion were discussed. The results predict that smaller particles heat up faster during initial heating and higher laser input has the same effect. And, higher oxygen content raises the sustained combustion temperature and shortens the combustion period.

\section{Acknowledgments}

The authors would like to express their sincere thanks to the Materials Information Science Group of the Institute for Materials Research, Tohoku University, for their continuous support of the HITAC S-3800/380 supercomputing facilities.

\section{Nomenclature}

$C:$ mole concentration of gas $\left(\mathrm{mol} / \mathrm{m}^{3}\right)$

$C p_{\mathrm{p}}, C p_{\mathrm{g}}: \quad$ specific heats of particle and gas $(\mathrm{J} / \mathrm{kg} \cdot \mathrm{K})$

$D:$ molecular diffusion coefficient $\left(\mathrm{m}^{2} / \mathrm{s}\right)$ 


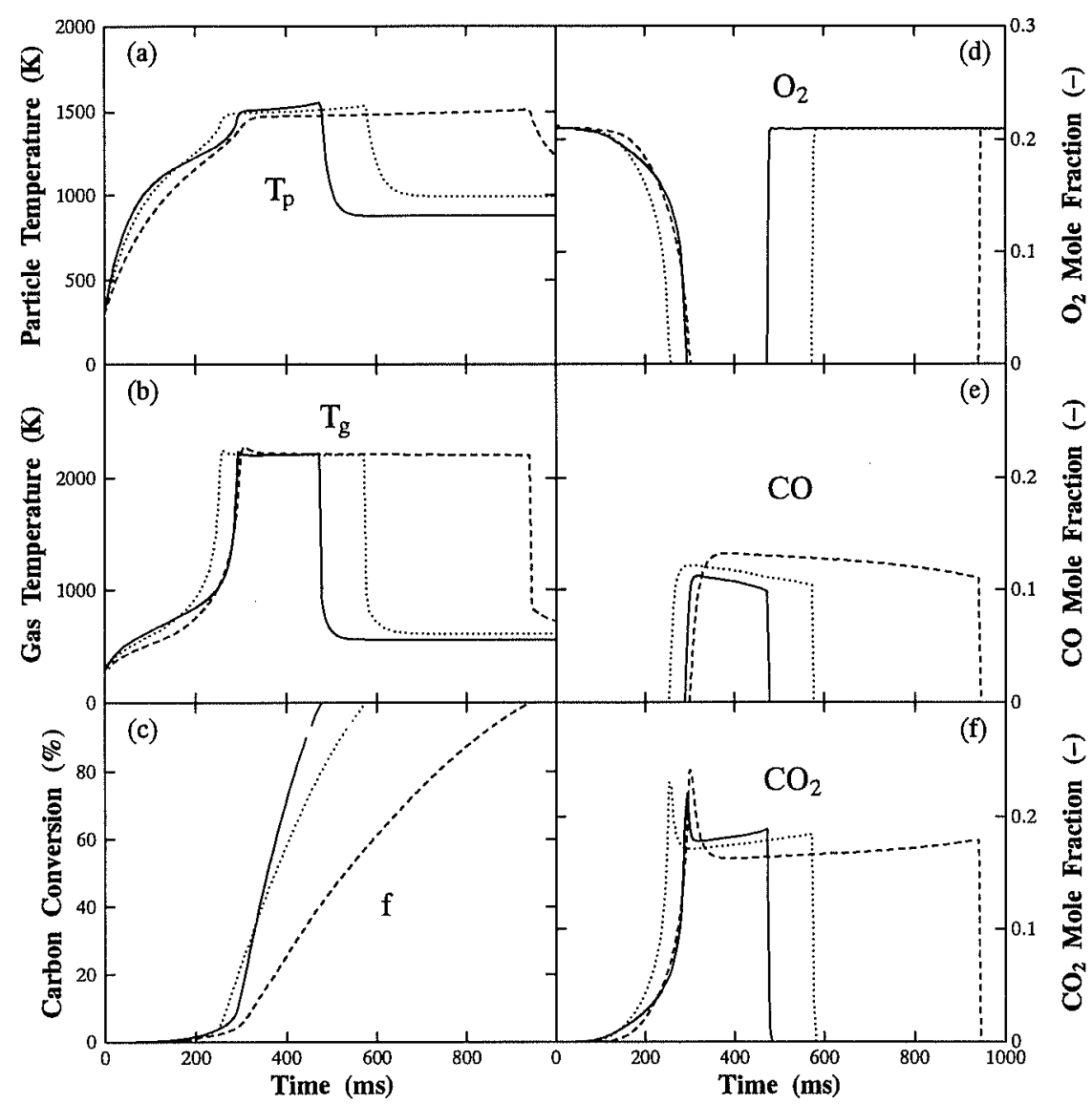

Fig. 10. Effects of particle size on coal char combustion. (Laser input $=1.85 \mathrm{~W} / \mathrm{mm}^{2}, \mathrm{O}_{2}=21 \%$ )

(a) Particle temperature, (b) gas temperature, (c) carbon conversion, (d) $\mathrm{O}_{2}$ mole fraction, (e) CO mole fraction, (f) $\mathrm{CO}_{2}$ mole fraction

Gas temperature and contents are at $0.05 \mathrm{~mm}$ from the particle surface.

$-D_{\mathrm{p}}=0.3 \mathrm{~mm}, \cdots D_{\mathrm{p}}=0.2 \mathrm{~mm}, \cdots--D_{\mathrm{p}}=0.15 \mathrm{~mm}, \cdots D_{\mathrm{p}}=0.10 \mathrm{~mm}$

$D_{\mathrm{p}}:$ particle diameter $(\mathrm{m})$

$h$ : heat transfer coefficient $\left(\mathrm{W} / \mathrm{m}^{2} \cdot \mathrm{K}\right)$

$M$ : molecular weight $(\mathrm{kg} / \mathrm{mol})$

$P$ : gas pressure (atm)

$Q_{1}, Q_{2}$ : heats of Reactions (1) and (2) (J/s)

$Q_{3}$ : heat of Reaction (3) $\left(\mathrm{J} / \mathrm{m}^{3} \cdot \mathrm{s}\right)$

$Q_{\mathrm{d}}$ : heat of molecular diffusion $\left(\mathrm{J} / \mathrm{m}^{3} \cdot \mathrm{s}\right)$

$Q_{\mathrm{L}}$ : laser input energy $(\mathrm{J} / \mathrm{s})$

$Q_{N}$ : conduction heat between gas and solid particle $(\mathrm{J} / \mathrm{s})$

$Q_{\mathrm{rg}}:$ radiant heat in control volume of gas $\left(\mathrm{J} / \mathrm{m}^{3} \cdot \mathrm{s}\right)$

$Q_{\mathrm{rs}}$ : radiant heat from particle surface $(\mathrm{J} / \mathrm{s})$

$r$ : distance from the center of particle $(\mathrm{m})$

$R$ : gas constant $(8.314 \mathrm{~J} / \mathrm{mol} \cdot \mathrm{K})$

$R_{1}, R_{2}$ : reactions rate (1) and (2) $(\mathrm{kg} / \mathrm{s})$

$R_{3}$ : reaction rate $(3)(\mathrm{kg} / \mathrm{s})$

$S:$ surface area of a particle $\left(\mathrm{m}^{2}\right)$

$S_{\mathrm{v}}$ : input or output area of gas control volume $\left(\mathrm{m}^{2}\right)$

$t:$ time (s)

$T_{\mathrm{p}}, T_{\mathrm{g}}$ : temperatures of a particle and gas (K)

$T_{0}$ : temperature of bulk gas (K)

$V_{\mathrm{p}}, V_{j}:$ volumes of particle and control volume $\left(\mathrm{m}^{3}\right)$

$Y$ : mole fraction of gas $(-)$

$Y_{0}$ : mole fraction of bulk gas $(-)$

$\alpha$ : laser absorptivity of a particle (-) $\beta:$ stoichiometric coefficient ( - )

$\varepsilon_{\mathrm{p}}, \varepsilon_{\mathrm{g}}:$ emmisivities of a particle and gas (-)

$\lambda$ : conduction heat coefficient $(\mathrm{W} / \mathrm{m} \cdot \mathrm{K})$

$\xi$ : disproportionation factor for heat released to solid (一)

$\rho_{\mathrm{p}}, \rho_{\mathrm{g}}:$ densities of particle and gas $\left(\mathrm{kg} / \mathrm{m}^{3}\right)$

$\sigma:$ Stefan-Boltzmann constant $\left(5.669 \times 10^{-8} \mathrm{~W} / \mathrm{m}^{2} \cdot \mathrm{K}^{4}\right)$

$v:$ gas velocity $(\mathrm{m} / \mathrm{s})$

$\varphi$ : mass velocity of gas $\left(\mathrm{kg} / \mathrm{m}^{2} \cdot \mathrm{s}\right)$

$\Delta r:$ thickness of control volume (m)

Subscripts

$i: \quad$ gas species

$j:$ numbers of control volume

$k$ : numbers of control volume

$N$ : a number of control volumes

$\delta$ : numbers of control volume through which radiant heat pass

\section{REFERENCES}

1) D. Zhang, T. F. Wall and P. C. Hills: Fuel, 73 (1994), 647.

2) Y. de Lassat de Pressigny, M. Picard, G. Prado, H. Aleboyeh and O. Simonin: 49th Ironmaking Conf. Proc., AIME, (1990), 473

3) M. Qu, M. Ishigaki and M. Tokuda: Fuel, 75 (1996), 1155.

4) P. A. Libby and T. R. Blake: Combustion Flame, 36 (1979), 139.

5) P. A. Libby and T. R. Blake: Combustion Flame, 41 (1981), 123.

6) C. W. Lau and S. Niksa: Combustion Flame, 90 (1992), 45. 
7) H. S. Caram and N. R. Amundson: Ind. Eng. Chem. Fundam., 16 (1977), 171.

8) E. Mon and N. R. Amundson: Ind. Eng. Chem. Fundam., 17 (1978), 313

9) K. Matsui and H. Tsuji: Combustion Flame, 70 (1987), 79.

10) K. Matsui and H. Tsuji: Combustion Flame, 81 (1990), 86.

11) J. I. Morell and N. R. Amundson: Chem. Eng. Sci., 45 (1990), 3247.

12) A. M. Kanury: Introduction to Combustion Phenomena, Gordon and Breach Science Publishers, New York, (1975), 81.

13) Ösüm, A. Chambers, G. Kovacik and M. Oguztöreli: Can. J. Chem. Eng., 69 (1991), 1142

14) B. J. Waters, R. E. Mitchell, R. G. Squires and N. M. Laurendau: Combustion Flame, 74 (1988), 91.

15) Y. Yamamoto, Y. Ito, J. Yuan, I. Naruse and K. Ootake: $J$. JSME B, 59 (1993), 220.

16) H. W. Batchelder, R. M. Busche and W. P. Armstrong: Ind. Eng. Chem., 45 (1953), 1856.

17) T.X. Phuoc and D. J. Maloney: 22nd Symp. (Int.) on Combustion,
The Combustion Inst., Pittsburgh, (1988), 125.

18) D. Zhang: Combustion Flame, 90 (1992), 134

19) J. C. Chen, M. Taniguchi, K. Narato and K. Ito: Combustion Flame, 97 (1994), 107.

20) M. A. Field: Combustion Flame, 13 (1969), 237

21) High Temperature Reaction Rate Data, The University, Leeds, Vol. 1-5, (1968-1970).

22) M. M. Baum and P. J. Street: Combustion Sci. Technol., 3 (1971), 231

23) J. Goldman, D. Xieu, A. Oko, R. Mikne and R. H. Essenhigh: 20th Symp. (Int.) on Combustion, The Combustion Inst., Pittsburgh, (1984), 1365.

24) R. K. Boyd and J. H. Kent: 21st Symp. (Int.) on Combustion, The Combustion Inst., Pittsburgh, (1986), 265.

25) X. Luo, R. K. Boyd and J. H. Kent: J. Inst. Energy, 64 (1991), 230.

26) H. C. Hottel: Radiant Heat Transmission, Chap. 4, in W. H. McAdams, Heat Transmission, 3rd Ed., McGraw-Hill Book Company, New York, (1954). 